\title{
Correlation between Body Mass Index and Age at Menarche
}

\author{
Atika Primandina Putri, ${ }^{1}$ Yulia Sofiatin, ${ }^{2}$ R. M. Ryadi Fadil, ${ }^{3}$ Hadyana Sukandar, ${ }^{2}$ Nugroho \\ Harry Susanto, ${ }^{2}$ Anggraini Widjadjakusuma, ${ }^{2}$ Lulu Eva Rakhmilla, ${ }^{2}$ Lola Ilona ${ }^{2}$ \\ ${ }^{1}$ Faculty of Medicine, Universitas Padjadjaran, ${ }^{2}$ Department of Epidemiology and Biostatistics, \\ Faculty of Medicine Universitas Padjadjaran ${ }^{3}$ Department of Child Health Faculty of Medicine \\ Universitas Padjadjaran/Dr. Hasan Sadikin General Hospital Bandung
}

\section{Abstract}

Background: The decline of age at menarche has been reported in several countries, it occurred because of genetic, ethnic, and socioeconomic improvement in nutritional status and environment. The improvement of nutritional status has occurred globally all over the world including in Indonesia. One of the measuring tools in nutritional status is body mass index (BMI). The objective of the study was to assess the correlation between BMI and age at menarche.

Methods: A cross-sectional study was carried out among girls aged 9-15 years old in Jatinangor, from May-November 2013. The sample of this study was chosen with cluster random sampling. Age at menarche information was collected through a questionnaire. Body mass index was calculated from measurement of body weight and height. Data was analyzed using Spearman correlation test.

Results: Out of three hundred and sixty nine subjects participating in this study, sixty seven were included in the inclusive criteria. According to the classification of BMI of underweight, normal, overweight, and obese, there were $1,55,8$, and 3 persons, respectively. Mean of BMI was 19.04 and mean age at menarche was 12.72 years, which showed a non significant result $(r=-0.013 ; p=0.458)$.

Conclusions: Age at menarche was not correlated with BMI. [AMJ.2015;2(4):521-4]

Keywords: Adolescent girls, age at menarche, body mass index

\section{Introduction}

Puberty is one of the crucial stages in human growth and development process. One of the signs of puberty is menarche. ${ }^{1}$ Over last few decades, puberty has occurred earlier so that the age at menarche decreased. This situation occured in the Unites States, South Korea, and Indonesia. ${ }^{2-4}$ In Indonesia, there was a decline of age at menarche to 12.96 years from 13.22 years in 1996.4 This might be due to the evolving of better socioeconomic conditions, nutrition and health status. ${ }^{1}$ Onset of menarche can be affected by various factors, such as ethnicity, socioeconomic, genetic and nutritional status. ${ }^{2,4,6,7}$

Menarche is the first menstruation that occurred in a cycle. Menarche is regulated by hormones, such as gonadotropin releasing hormone $(\mathrm{GnRH}){ }^{1}$ Gonadotropin releasing hormone could be affected by leptin. The increasing level of leptin will trigger the activation of $\mathrm{GnRH}$ and accelerate the initiation of puberty. ${ }^{1,8}$ Leptin can increase when there are elevated adipose cell and leptin resistance. ${ }^{9}$ Elevated adipose cells can be associated with elevated BMI. The easiest way to measure nutritional status is by measuring the Body Mass Index. Body mass index is a ratio between weight and height that could indicate the composition of body fat. ${ }^{10}$ The decline of age at menarche can be the risk factor for various diseases, such as insulin resistance, depression in teenager, engages in risk behaviors, breast cancer and cardiovascular risk. ${ }^{11-13}$ The aim of the study was to analyze the correlation between Body Mass Index and the age at menarche.

\section{Methods}

A cross-sectional study was carried out among girls aged 9-15 years in elementary and junior high schools in Jatinangor, Sumedang. This research was conducted in May-November 2013. The inclusion criteria of this study were

Correspondence: Atika Primandina Putri, Faculty of Medicine, Universitas Padjadjaran, Jalan Raya Bandung-Sumedang Km.21, Jatinangor, Sumedang, Indonesia, Phone: +62 85270242423 Email: atikaprimandina@gmail.com 
Table 1 Distribution of Age at Menarche and Body Mass Index ( $n=67)$

\begin{tabular}{lcc}
\hline \multicolumn{1}{c}{ Variable } & Number of Person & Percentage (\%) \\
\hline Age at Menarche (Years) & 3 & 5 \\
11 & 25 & 37 \\
12 & 28 & 42 \\
13 & 10 & 15 \\
14 & 1 & 1 \\
15 & & \\
Body Mass Index & 1 & 2 \\
Underweight & 55 & 82 \\
Normal & 8 & 12 \\
Overweight & 3 & 4 \\
Obese & & \\
\hline
\end{tabular}

young girls living in Jatinangor with maximum menstrual period less than four months, assumed that they had not been affected yet by growth spurt. ${ }^{14}$ Then, the sample size was calculated by using calculation for analytic numeric study with minimum sample size of 53 subjects.

Subjects were selected by cluster random sampling, Three elementary and five junior high schools in Jatinangor were chosen. This study has been approved by the Health Research Ethics Committee of the Faculty of Medicine, Universitas Padjadjaran, Department of Education Sumedang, and Department of Regional Development Sumedang. .

In this study the independent variable was BMI which was derived by measuring height and weight. The height was measured by using microtoise, then the subjects were asked to take off their shoes and caps, and standup, with heels, buttock, shoulders and back of the head touching the wall. The Frankfort area must be perpendicular to the wall and parallel to the floor. Next, the weight was measured by using a weighing scale and subjects must take off their shoes, jackets, heavy clothes and other stuff. The dependent variable of this study was the age at menarche, determined by questionnaires that must be filled by the subjects. Thecollected data were analyzed using Spearman correlation

\section{Results}

Out of the 369 girls of the selected schools, 85 subjects met the inclusion criteria, and eighteen of them were excluded due to incomplete data.
The rest of the subjects reached the minimum sample size and were analyzed.

The earliest age at menarche was 11 and occurred in 3 adolescent girls with underweight and normal BMI. Most of the girls got their first menstruation at age 13 and had normal BMI (Table 1).

According to the analysis of Spearman correlation test, the correlation value (r) derived in this study was 0.013 and inversely correlate, $p$ value was 0.458 ( $p>0.05)$. The result of this study indicated that there was no significant correlation between both variables.

\section{Discussions}

The population and subject of this study were girls aged 9-15 years. The average age at menarche according to the survey, was 12-14 years old. The youngest age at menarche was 9 years and the oldest one was 18 years. ${ }^{4}$ The mean age of menarche in Jatinangor in this study was 12.72 years which was younger than the national mean age at menarche in 1996 (13.22 years old). ${ }^{5}$ This decline could be due to improvement in nutritional status and environmental changes. ${ }^{6}$ The mean age of menarche in this study was higher compared to studies in Kuwait15 (12.41 years old) and United States ${ }^{2}$ (12.32 years old), but was lower than the study in South Korea ${ }^{3}$ (13.1 years old). The differences might be due to sexual maturity variation by race, ethnicity and nutritional status. ${ }^{16,17}$

Out of 67 subjects, $83 \%$ had normal BMI and reached menarche at the age of 13 years. The 
body mass index distribution in this study was widely varied, the overweight and obese group percentage were $12 \%$ and $4 \%$ respectively (Table 1). The prevalence of overweight and obese in this study was different from studies in Medan18 (27\%) and in Kuwait ${ }^{15}(18.3 \%$ and $25.8 \%)$. In this study, girls who got their first menarche were from underweight and normal BMI. Normally, girls with earlier menarche has higher BMI, as shown in the Bogalusa Heart Study ${ }^{17}$ and in the study of Oh et al. ${ }^{3}$ in South Korea.

Furthermore, this study showed that there was no correlation between age at menarche and BMI. This was contradictive to studies of Oh et al. ${ }^{3}$ in Seoul, South Korea, the Bogalusa Heart Study ${ }^{17}$ and of Olivia in Medan ${ }^{18}$, which reveals a correlation between BMI with onset at menarche. This difference might be due to differentdesign, criteria, operationaldefinition, and difference in obesity prevalence. ${ }^{19}$

Additionally, Robert et al. ${ }^{20}$ in Chicago, Illinois also stated that menarche shows significantly a tendency to occur in preteen girls with an elevated BMI which is related to the increasing level of leptin. Based on a study by Apter ${ }^{9}$ in female adolescence, leptin shows a correlation with body weight and puberty. Ethnic, genetic and environment might be other reasons for this difference. ${ }^{6}$

There are some limitations and recommendation for this study. The body mass index on onset of menarche should be measured at the first menstrual period. ${ }^{1,10}$ Therefore, the use of a cohort study design and consideration of lower overweight and obesity prevalence will reveal a better conclusion. Leptin is more directly correlated with body fat composition and should be considered to be used in a further study as an independent variable for onset of menarche. ${ }^{9}$ Other factors that can affect menarche, such as socioeconomic, genetic and ethnicity should be taken into account. Based on this study, it can be concluded that there is no correlation between BMI and age at menarche in Jatinangor.

\section{References}

1. Gardner DG, Shoback DM, Greenspan FS. Greenspan's basic and clinical endocrinology. San Fransisco: McGrawHill Medical; 2007.

2. McDowell MA, Brody DJ, Hughes JP. Has age at menarche changed? Results from the National Health and Nutrition Examination Survey (NHANES) 1999-2004. J Adolesc
Health. 2007;40(3):227-31.

3. Oh CM, Oh IH, Choi KS, Choe BK, Yoon TY, Choi JM. Relationship between body mass index and early menarche of adolescent girls in Seoul. J Prevent Med Publ Health. 2012;45(4):227-34.

4. Batubara JR, Soesanti F, van de Waal HD. Age at menarche in Indonesian girls: a national survey. Acta Med Indones. 2010; 42(3):78-81.

5. Hendrawati LD, Glinka J. Age at menarche in Indonesia. Folia Medica Indonesiana. 2003;39(1):18-21.

6. Karapanou 0, Papadimitriou A. Determinants of menarche. Reprod Biol Endocrinol. 2010;8:115.

7. WronkaI,Pawlinska-Chmara R. Menarcheal age and socio-economic factors in Poland. Ann Hum Biol. 2005;32(5):630-8.

8. Molina PE. Endocrine physiology. New Orleans, Louisiana: McGraw-Hill; 2006.

9. Apter D. The role of leptin in female adolescence. Annal NY Acad Sci. 2003; 997(1):64-76.

10. Whitney EN, Rolfes SR. Understanding nutrition. Belmont, CA: Thomson Higher Education; 2008.

11. Parent AS, Teilmann G, Juul A, Skakkebaek $\mathrm{NE}$, Toppari J, Bourguignon JP. The timing of normal puberty and the age limits of sexual precocity: variations around the world, secular trends, and changes after migration. Endocr Rev. 2003;24(5):66893.

12. Sloboda DM, Hart R, Doherty DA, Pennell CE, Hickey M. Age at menarche: influences of prenatal and postnatal growth. J Clin Endrocrinol Metab. 2007;92(1):46-50.

13. Gaudineau A, Ehlinger V, Vayssiere C, Jouret B, Arnaud C, Godeau E. Factors associated with early menarche: results from the French Health Behaviour in School-aged Children (HBSC) study. BMC Public Health. 2010;10(1):175.

14. Kawulur EIJJ, Suryobroto B, Budiarti S, Hartana A. Association of sexual maturation and body size of Arfak children. Hayati J Biosci. 2012;19(3):124-30.

15. Al-Awadhi N, Al-Kandari N, Al-Hasan T, AlMurjan D, Ali S, Al-Taiar A. Age at menarche and its relationship to body mass index among adolescent girls in Kuwait. BMC Public Health. 2013;13(1):29.

16. Reagan PB, Salsberry PJ, Fang MZ, Gardner WP, Pajer K. African-American/ white differences in the age of menarche: accounting for the difference. Soc Sci Med. 2012;75(7):1263-70. 
17. Freedman DS, Khan LK, Serdula MK, Dietz WH, Srinivasan SR, Berenson GS. Relation of age at menarche to race, time period, and anthropometric dimensions: the Bogalusa Heart Study. Pediatrics. 2002;110(4):e43.

18. Olivia D, Deliana M, Supriatmo, Hakimi, Lubis SM. Body mass index and age of menarche in young girls. Paediatr Indones. 2012;52(6):309-12.

19. Bralić I, Tahirović H, Matanić D, Vrdoljak
O, Stojanović-Špehar S, Kovačić V, et al. Association of early menarche age and overweight/obesity. Pediatr Endocrinol Metab. 2012;25(1-2):57-62.

20. Rosenfield RL, Lipton RB, Drum ML. Thelarche, pubarche, and menarche attainment in children with normal and elevated body mass index. Pediatrics. 2009;123(1):84-8. 